\title{
Unknown If Ever Smoked
}

National Cancer Institute

\section{Source}

National Cancer Institute. Unknown If Ever Smoked. NCI Thesaurus. Code C67151.

Indicates that a person's smoking status is unknown. 